\title{
Interactive comment on "Radar-Based Quantitative Precipitation Estimation for the Identification of Debris-Flow Occurrence over Earthquake affected Region in Sichuan, China” by Zhao Shi et al.
}

\section{Anonymous Referee \#2}

Received and published: 19 October 2017

General Comments: This manuscript investigates the debris flow occurrence using rainfall Intensity-Duration (I-D) information in the earthquake-affected areas in Sichuan, China. Two S-band Doppler radars are used to estimate rainfall in the study domain characterized by complex terrain. Therein, traditional Z-R relations are adopted with additional attention paid to vertical profile of reflectivity (VPR) correction and Kalman filter based bias correction. The I-D curves are then calculated using a frequentist approach with the radar derived rainfall products.

Printer-friendly version

Discussion paper

Overall, this topic well fits the scope of NHESS. The methodology used in the paper 
is scientifically sound. The study shows several valuable scientific results, which can possibly be used for guidance of debris flow warnings. Nevertheless, some minor changes will improve paper clarity. Specific comments are listed below: 1. The writing needs to be improved. Please proofread the manuscript before submitting the revised version. Specific examples of mistakes are presented below: 1.1. Page 2, Line 15: highly rely-> highly relies 1.2 . Page 3 , Line 1 : have to be $->$ has to be 1.3 . Page 25, caption of Figure 7: event->events 1.4. Page 26, caption of Figure 8: possibility$>$ probability

2. Reference formatting should be more consistent throughout the manuscript. There are numerous references that are not cited in correct form. For examples, Qiang W. et al., 2015; Xiaojun G. et al 2016; Michele C. et al., 2015; Francesco M. et al., 2014; and many others.

Additional Related Reference: Willie, D., H. Chen, and V. Chandrasekar, et al., 2017: Evaluation of Multisensor Quantitative Precipitation Estimation in Russian River Basin. Journal of Hydrologic Engineering, 22(5), E5016002, doi: 10.1061/(ASCE)HE.19435584.0001422 .

3. Page 2, Line 14: Early Warning System Using acronym would be enough since it had been mentioned earlier.

4. Page 4, Line 5: performance specifications->system specifications

5. Page 5, Lines 14-16: The authors are using different tilt data trying to obtain rainfall estimates at the same vertical level. What is the purpose of doing this? Getting rainfall closer to surface might be more useful (provided that lowest level data is not blocked).

6. Page 6, Line 23: The rationale of using these two Z-R relations is insufficient. It is well known that Z-R is greatly dependent on local rainfall microphysics. A local DSDbased variability analysis would be helpful.

Printer-friendly version

7. Page 15, Table 1: doppler->Doppler

Discussion paper

Interactive

comment

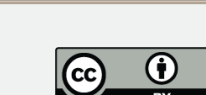


8. Page 15, Table 1: The pulse width seems not matching with the range resolution. Please clarify.

NHESSD

Interactive comment on Nat. Hazards Earth Syst. Sci. Discuss., https://doi.org/10.5194/nhess2017-308, 2017.

Interactive

comment 